\title{
Online Learning Anxiety and Self-Efficacy of Chinese EFL Learners Under Pandemic Situation
}

\author{
Duo Yun (Corresponding author) \\ English Department, Dalian Neusoft University of Information \\ No.8 Software Park Road, Dalian, China \\ E-mail: claudia96@foxmail.com
}

Jianying Zhang

English Department, Dalian Neusoft University of Information

No.8 Software Park Road, Dalian, China

Received: October 5, 2020 Accepted: November 12, 2020 Published: November 24, 2020

doi:10.5296/ijl.v12i6.17983

URL: https://doi.org/10.5296/ijl.v12i6.17983

\begin{abstract}
The present study aims to find out the anxiety of Chinese EFL learners as well as its relationship with self-efficacy in the online learning environment. A total of 492 Chinese college students from different regions participated in the research. The data obtained from the questionnaire survey were submitted to SPSS version 25.0 to do analysis. The results revealed that: (1) most English learners have a relatively high level anxiety toward online learning under the special pandemic situation, and the anxiety varies among students of different academic years; (2) there is a weak negative correlation between learning anxiety and self-efficacy (3) Anxiety affects self-efficacy in a negative way. More specifically, teaching mode and external environment have a significantly negative effect on self-efficacy.
\end{abstract}

Keywords: Learning anxiety, Self-efficacy, EFL, Pandemic situation

\section{Introduction}

The network has created various forms of life, work and study with the rapid development of information technology. Nowadays, education and science are not limited by time, space and place, and the ways students acquire knowledge have become flexible and diverse. The educational institutions also begin to use online teaching mode. In order to adapt to the 
situation, many universities makes great efforts in building their own college English network teaching platform, college English online learning center, and targeted development of network teaching resources (Lu \& Ren, 2012). Students can learn through MOOCS and other online videos after face-to-face learning so as to enrich their knowledge.

Due to the continuous development of the pandemic situation in 2020, online class has become an indispensable part of teaching and learning. It is undoubtedly the best way to study in the special situation and abundant online resources can better help students strengthen learning. However, online learning also brings a lot of problems. In online classroom, teachers have difficulty to detect the changes of students' psychology and emotion. Students' autonomous learning ability is also unstable. What's more, online learning inclines to be influenced by other external factors, such as network connections and students' computer operation levels. Those factors usually cause learning anxiety, which can easily lead to the decline of self-efficacy. Therefore, emotion plays a very important role in language learning.

There has been a notable increased interest on learning emotion in the field of educational psychology. In previous studies, many researchers have studied learning anxiety (e.g., Zhao, 2017; Yin, 2011; Wang, 2019; Chen \& Luo, 2012). But most of the previous studies focused on the examination of anxiety in traditional classroom, and only a few of them took the personal characteristics, including participants' gender, age and other education background information into account. For example, Debreli studies the degree and source of oral anxiety of English learners through comparing the difference between age, language proficiency and gender (2015). In Bandura's four influencing factors of self-efficacy, it has been pointed out that there is an interaction between emotion and self-efficacy (1982). Theoretically, anxiety might be associated with self-efficacy. However, few researchers examined the relationship between anxiety and self-efficacy and few descriptions concerning how the two factors interact with each other can be found. This may make it difficult for researchers and English teachers to take measures to help students learn efficiently online.

The purpose of this study is to explore the anxiety level of Chinese EFL college students in online English Courses, the relationship between learning anxiety and self-efficacy and the influence of learning anxiety on self-efficacy. It is expected to provide reference and enlightenment for the improvement and further promotion of online teaching in colleges and universities.

Guided by the research purpose, the present study aims to answer the following questions:

(1) Under the pandemic situation, what is the anxiety level of Chinese EFL college students in online English Courses?

(2) How does learning anxiety vary by individual learner characteristics?

(3) What is the relationship between learning anxiety and self-efficacy in online English education?

(4) To what extent does learning anxiety predict self-efficacy? 


\section{Literature Review}

\subsection{Definition of Related Concepts}

\subsubsection{Foreign Language Learning Anxiety}

Anxiety comes from the German word "angst". Before 1950, only a few books discussed anxiety. A large number of studies on anxiety appeared after Freud's The Interpretation of Dreams. As there are many potential causes and intensity of anxiety, so far, there is no unified view on the definition of anxiety and the nature of anxiety. American psychologist Spielberger defines anxiety as the subjective feeling of tension, apprehension, nervousness, and worry associated with an arousal of the autonomic nervous system (1972). Foreign language learning anxiety was proposed by Horwitz in 1986, which is a type of anxiety. Horwitz points out that foreign language learning anxiety is a unique and complex language learning process which integrates the concepts of self-cognition, belief, feeling and behavior related to classroom language learning (1986).

\subsubsection{Self-Efficacy}

Self-efficacy refers to people's subjective judgment on whether they can succeed in a certain achievement behavior (Bandura, 1982). Bandura points out in his motivation theory that human behavior is influenced by the result factor and the antecedent factor. The result factor of behavior is reinforcement, which can stimulate and maintain the motivation of behavior to regulate and control human behavior. Therefore, he believes that the emergence of behavior is not the result of aftereffect reinforcement, but the expectation of the next step of reinforcement after recognizing the dependency between behavior and reinforcement. Self-efficacy can determine the individual's choice and persistence of activities, affect the individual's attitude towards difficulties, the acquisition of new behaviors and the performance of acquired behaviors, as well as the emotional state of individuals in activities (1982).

\subsection{Previous Study on Learning Anxiety and Self-Efficiency}

\subsubsection{Foreign Language Learning Anxiety}

Up to now, a large number of studies on foreign language learning anxiety have revealed the main sources and causes of anxiety. Horwitz proposed the FLCAS in 1986. Foreign language learning anxiety is divided into three dimensions: communication anxiety, examination anxiety and fear of negative evaluation anxiety, which has made great contributions to the further study of foreign language anxiety in future generations. In the research of Debreli, the factors that cause anxiety are dysphonia, being asked directly by the teacher, not understanding the questions asked by the teacher, etc (2015). Karatas analyzes the level of foreign language anxiety from the perspective of gender, and shows that female college students are more anxious than male college students. They also points out self-comparison of others will make learners show more competitive behavior (2016). Xue explains from the perspective of secondary vocational English learners that different teaching designs can also bring foreign language learning anxiety to students (2011). In the study of English class 
model of students' learning anxiety, it was found that flipped classroom model can reduce students' foreign language learning anxiety and give full play to students' autonomy. (Wang, 2016; Chang \& Lin, 2018).

\subsubsection{Online English Learning Anxiety and Self-Efficiency}

Online English learning anxiety refers to the sense of frustration and self-blame that English learners feel at a loss when they are faced with problems that are difficult to overcome in the process of classroom learning or after class learning by using network multimedia or computer technology under the network environment, which eventually damages the learners' self-confidence and self-esteem and causes anxiety (Zhao, 2017). In the research of Yin, he founds that the causes of online foreign language learning anxiety are the lack of humanistic care, the lack of online learning strategies, online test anxiety and negative evaluation fear, information surplus and lack of network skills (2011). Wang Fang from the perspective of the class environment explains that under the network environment, students are not willing to take the initiative to speak actively, they are confused about various learning resources, and teachers lack guidance for students, which also causes anxiety (2019). Chen and Luo have studied that the reasons for non-English majors' online foreign language learning anxiety lie in the form of class and the pressure of the second language learning (2012).

In foreign language learning on anxiety and self-efficacy, researchers emphasize how to ease anxiety according to self-efficacy or the relationship between learning anxiety and self-efficacy between non-native English students and English speaking students. Dai based on the theory of self-efficacy, from the four factors influencing the formation of self-efficacy, discusses the effective countermeasures to alleviate the anxiety of foreign language classroom learning (2019). Haley found that there was a negative correlation between language anxiety and self-efficacy of non-native English students (2015).

\subsection{Summary}

Through reading the previous literature, we can see anxiety is a problem that cannot be ignored in the process of language learning. The previous study of foreign language learning anxiety is mainly based on the traditional classroom model, and focuses on gender, language level, age and other aspects. However, there are few researches on the relationship between foreign language online learning anxiety and self-efficacy of Chinese EFL college students. Based on the FLCAS scale with high reliability and validity, combined with the new background of online learning of college students caused by the current pandemic situation, this study discusses the level of online learning anxiety and explores the correlation and influence of online learning anxiety and self-efficacy of Chinese EFL college students with a large sample size of more than 400 participants, and also analyzes their relationship from multiple perspectives, which plays a comprehensive and guiding role. 


\section{Methodology}

\subsection{Participants}

Table 1. Demographic information

\begin{tabular}{lll}
\hline & Frequency & Percent \\
\hline Gender & & \\
\hline Male & 90 & $18.0 \%$ \\
\hline Female & 402 & $80.2 \%$ \\
\hline Grade & & \\
\hline Freshman & 192 & $38.3 \%$ \\
\hline Sophomore & 192 & $38.3 \%$ \\
\hline Senior & 99 & $19.8 \%$ \\
\hline
\end{tabular}

School Type

\begin{tabular}{lll}
\hline Public Universities & 95 & $19.0 \%$ \\
\hline Private Universities & 382 & $76.2 \%$ \\
\hline Vocational Colleges & 15 & $3.0 \%$ \\
\hline Total & 492 & 100.0 \\
\hline
\end{tabular}

In this study, a total of 492 Chinese EFL college students volunteered to participate. They come from different regions of China, different schools and different grades. The English proficiency of the participants was also different. Demographic information on the participants is provided by grade, gender, institution type, frequency and percentage, as shown in the Table 1 above.

Five participants in the questionnaire were invited to the semi-structured interview. Five interviewers all come from the same university and same grade. Three of them major in English and two of them major in Business English. All of them are female. All of them have different English proficiency and academic performance.

\subsection{Data Collection Instruments}

In the study, the data were collected with mixing research method, questionnaire and follow-up interview.

\subsubsection{Questionnaire}

The questionnaire used in this paper is based on the FLCAS which has been widely accepted by Horwitz and other scholars. It involves classroom communication, class study and examination, network environment and other aspects to test foreign language learning anxiety. Classroom communication involves whether one is worried about his performance in class because he can't directly see the teacher's expression and whether he can take the initiative to answer questions in the course. Course preparation and review and online examination constitute the class study and examination. External environment comprise online learning resources and network technology. Teaching mode represents the attitude towards online teaching. In order to measure the level of English learning anxiety, a number of 11 anxiety 
statement-type question items were designed. All the question items adopted 5-point Likert-scale, ranging from "strongly disagree" (1) to "strongly agree" (5) The total score varies from 11 points to 55 points ( 1 point for each item is equal to 11 points of the lowest total score, and 5 points for each item is equal to 165 points of the highest score).

Based on FLCAS, the paper also adds the items of self-efficacy. This is also a 5-point Likert-scale, in which participants are asked to express their degree of agreement from "strongly disagree" (1) to "strongly agree" (5) on the topic so as to measure their self-efficacy. The final questionnaire contains 25 items. Table 2 describes the internal reliability consistency of the questionnaire items. Five factors were submitted tov Cronbach Alpha analysis, and the results showed that all the coefficients were all above 0.75 , most of them were higher than 0.8 , which proves that the internal reliability of the questionnaire is high.

Table 2. Internal reliability consistency of the questionnaire items

\begin{tabular}{lllll}
\hline Item & $\begin{array}{l}\text { Question } \\
\text { Number }\end{array}$ & $\begin{array}{l}\text { Cronbach's } \\
\text { Alpha }\end{array}$ & Mean & Std.Deviation \\
\hline Self-efficacy & $9,10,11,12,13$ & .930 & 3.656 & 1.004 \\
\hline Teaching mode & $14,15,19$ & .856 & 3.337 & 1.199 \\
\hline Class Interaction & 16,17 & .834 & 3.078 & 1.217 \\
\hline Class Study and Examination & $18,20,21$ & .775 & 2.940 & 1.183 \\
\hline External environment & $22,23,24$ & .851 & 3.033 & 1.184 \\
\hline
\end{tabular}

\subsubsection{Semi-Structured Interviews}

The second instrument used in the study is semi-structured follow-up interview. This tool was chosen to collect detailed data on the sources and levels of anxiety of participants, and to further study the causes of their anxiety. In this study, the interview started with three main questions: whether online learning makes students anxious, the possible causes of anxiety and whether anxiety affects self-efficacy, which is further supported by follow-up questions and surveys. The interview mainly focuses on the views on online learning, the attitude in this process, how to solve the problems encountered and the biggest anxiety factor in learning.

\subsection{Procedures}

The author developed a questionnaire suitable for English learning and network environment on the basis of FLCAS, and added self-efficacy-related questions to the questionnaire after researching the literature. In May 2020, the online questionnaire was distributed to English majors in different universities/colleges from different regions across China. Data collection lasted for a week. In July 2020, in order to grasp further information, five participants were randomly selected for semi-structured interview to supplement the questionnaire survey. After collection, the interview data are sorted, classified and transcribed.

\subsection{Data Analysis}

The data obtained from the questionnaire were submitted to SPSS version 25.0 to do analysis. Independent sample T-test was used to test whether there was significant difference between 
gender and learning anxiety. ANOVA was used to test whether there were significant differences among grade, institution type and learning anxiety. Correlation analysis was used to test the correlation between learning anxiety and self-efficacy. After confirming the correlation between the two factors, linear regression analysis was carried out to further explore how learning anxiety affects self-efficacy.

After collecting the questionnaire data, 5 randomly selected volunteer students were interviewed around online anxiety learning, and the content of the interview was recorded. After the interview, the interview records are sorted out and the causes of online learning anxiety are summarized.

\section{Results and Discussion}

\subsection{The Anxiety Level of Chinese EFL College Students}

According to the anxiety scale of this questionnaire, a total score of more than 35 is interpreted as a higher level of learning anxiety, while a total score of 15 to 35 shows a moderate level of learning anxiety, and a total score of less than 15 indicates a lower level of foreign language learning anxiety (Horwitz et al., 1986). In order to determine the level of oral anxiety, the average score was calculated by descriptive statistics. (Table 3)

Table 3. Percentage and frequency of students' foreign language learning anxiety

\begin{tabular}{lll}
\hline & Percentages & Frequencies \\
\hline Low level of learning anxiety & 6.5 & 32 \\
\hline Moderate level of learning anxiety & 62.6 & 308 \\
\hline High level of learning anxiety & 30.9 & 152 \\
\hline Total & 100 & 492 \\
\hline
\end{tabular}

The results in Table 3 show that most students in this program experience moderate online English learning anxiety. The descriptive results reveal that $6.5 \%$ of the participants scored less than 15, indicating a low level of learning anxiety, while $62.6 \%$ of the participants scored 15-35, indicating that the level of learning anxiety was moderate. In addition, $30.9 \%$ of them scored higher than 35, indicating a higher level of learning anxiety. And among 492 participants, 387 had anxiety scores higher than 25 . In other words, most students seemed to have moderate or above learning anxiety.

The reasons for this result may be attributed to the unstable network environment of online learning, the lack of motivation in classroom communication, and the tolerance of uncertainty and ambiguity. Zhao Ziyuan's research on English learning anxiety of university students in network environment studied the anxiety problems in network English learning and obtains the similar results (2017). Yin Zhenyu first reviewed the foreign language classroom anxiety research, then analyzed the source of foreign language classroom anxiety under the network multimedia environment, and concluded that the causes of foreign language online classroom anxiety lie in network technology, lack of humanistic care, information surplus, etc (2011). 


\subsection{Learning Anxiety of Students of Different Characteristics}

It is supposed that learning anxiety vary by individual learner characteristics, including gender, grade and institution type. T-test and ANOVA were conducted to compare the English learning anxiety level of each group. Within the three groups, only students of different grades demonstrated significant differences in learning anxiety level. There are no significant differences in gender and institution type.

\subsubsection{The Difference of Learning Anxiety Among Students of Different Grades}

The results show that the average scores of learning anxiety of freshmen, sophomores and juniors are 30.61, 31.60 and 35.09 respectively. There was significant difference between freshmen, sophomores and juniors. In the post event comparison, there are significant differences between freshmen and juniors, and between sophomores and juniors (learning anxiety of freshmen $<$ learning anxiety of sophomores $<$ learning anxiety of juniors). The results of learning anxiety in each grade are shown in the table below.

There was no clearly significant difference in anxiety scores between freshmen and sophomores, but a certain gap between juniors and other grades was found. The reason that senior grade students have higher anxiety scores could be that they will face the problems of future development after graduation or probably are busy with things related to their own development. Online learning such as network environment is unstable, cannot communicate with teachers in a timely manner, which will make the seniors spend more time making up for online courses after class and take up their time for other tasks, thus the pressure of senior grade students is greater. In the semi-structured interview, five senior students were interviewed. Participants stated the following ideas:

"Remote homework is far more troublesome than offline, which undoubtedly reduces the time for me to learn postgraduate professional courses. "-Interviewee 3

"The online learning under the influence of the pandemic situation delayed my internship time. "-Interviewee 2

Table 4. Difference of learning anxiety among students of different grades

\begin{tabular}{lllllll}
\hline (I) grade & $(\mathrm{J})$ grade & $\begin{array}{l}\text { Mean } \\
\text { Difference } \\
\end{array}$ & $\begin{array}{l}\text { Std. } \\
\text { Er-J) }\end{array}$ & Sig. & & \multicolumn{2}{l}{ 95\% Confidence Interval } \\
\cline { 3 - 6 } Freshman & Sophomore & -.995 & .967 & .304 & -2.89 & .90 \\
\cline { 2 - 6 } & Junior & $-4.482^{*}$ & 1.172 & .000 & -6.78 & -2.18 \\
\hline \multirow{2}{*}{ Sophomore } & Freshman & .995 & .967 & .304 & -.90 & 2.89 \\
\cline { 2 - 6 } & Junior & $-3.487^{*}$ & 1.172 & .003 & -5.79 & -1.18 \\
\hline \multirow{2}{*}{ Junior } & Freshman & $4.482^{*}$ & 1.172 & .000 & 2.18 & 6.78 \\
\cline { 2 - 6 } & Sophomore & $3.487^{*}$ & 1.172 & .003 & 1.18 & 5.79 \\
\hline
\end{tabular}

*. The mean difference is significant at the 0.05 level.

It was found that the senior grade students were accompanied by the pressure of postgraduate 
entrance examination and employment while learning online. Because of the pandemic situation online learning, the internship cannot move forward according to the original plan, and the problems in the class cannot be solved in time, which makes them more worried about whether the undergraduate course learning can be carried out smoothly.

Due to the special situation this year, many senior students are caught off guard. Junior students all over the country spent the second half of their third year in online classes. The feeling of having a class at home for eight months is different from their former learning experience at school. The time passes faster, which pushes the students to the fork in the road of choice -- postgraduate entrance examination or employment. Students with firm goals continue to move towards their ideals, but those who have no goals or whose goals are not clear will be more likely to fall into anxiety and panic.

"Eight months after the outbreak, I feel very anxious at going back to school. I will take the exam when I am back. At the same time, I feel confused about the future."-Interviewee 5

Based on the changes brought about by the global pandemic and the pressure of graduation, the anxiety scores of senior online learning are higher than those of other grades.

\subsubsection{The Difference of Learning Anxiety Among Students of Different Genders}

According to the t-test, the results (Table 4) display surprisingly that there is no difference between male $(\mathrm{M}=33.57)$ and female $(\mathrm{M}=31.54 ; \mathrm{P}>0.05)$. However, in the past research on learning anxiety of different genders, the conclusion is different. Hakan Karatas et al.found out that female college students are more anxious than male college students (2016), and the research results of Wilson (2006) and Huang (2004) also confirmed this view. The reason for this phenomenon might be attributed to the different social testing background. The special background of this study is that due to the pandemic, all students have to take online courses at home. Regardless of the gender, all students have never studied in such a special situation, and it is easy to encounter unexpected situations during the class. At the same time, in the process of the pandemic, like closed management leads to reduced outside activities and low work efficiency, it will also have an impact on students' feelings, which will bring this feeling into learning and lead to high level of anxiety. However, the previous studies were carried out under normal social background and teaching conditions.

Table 5. Difference of learning anxiety among students of different genders

\begin{tabular}{|c|c|c|c|c|c|c|c|}
\hline & & & & & \multicolumn{3}{|c|}{ t-test for Equality of Means } \\
\hline gender & $\mathrm{N}$ & Mean & $\begin{array}{l}\text { Std. } \\
\text { Deviation }\end{array}$ & $\begin{array}{l}\text { Std. Error } \\
\text { Mean }\end{array}$ & $\mathrm{t}$ & df & $\begin{array}{l}\text { Sig. } \\
\text { (2-tailed) }\end{array}$ \\
\hline Male & 90 & 33.57 & 9.764 & 1.029 & 1.784 & 129.624 & .077 \\
\hline Female & 402 & 31.54 & 9.521 & .475 & & & \\
\hline
\end{tabular}

4.2.3 The Difference of Learning Anxiety Among Students of Different Institution Types

It can be seen from Table 5 that since $\mathrm{p}$ value is equal $0.798(\mathrm{P}>0.05)$, no significant difference of anxiety has been found between English learners of different institution types. 
Table 6. Difference of learning anxiety among students of different institution types

\begin{tabular}{llllll}
\hline & Sum of Squares & df & Mean Square & F & Sig. \\
\hline Between Groups & 41.616 & 2 & 20.808 & .226 & .798 \\
\hline Within Groups & 45092.798 & 489 & 92.214 & & \\
\hline Total & 45134.415 & 491 & & & \\
\hline
\end{tabular}

Generally speaking, it is supposed that anxiety levels vary among students of different universities with varying academic atmosphere and achievement motivation. However, in this research, there was no significant difference in anxiety level. This probably is also related to the global pandemic. In a survey on the learning, health and living conditions of college students during the pandemic initiated by the Youth League Committee of Donghua University, a total of 654 college students from different schools participated in this. It was found that nearly $90 \%$ of college students had different degrees of anxiety due to the pandemic. The investigation found that during this period, college students' learning and life style were impacted to varying degrees, which may have a significant impact on students' physical and mental health and learning effect. In order to prevent the escalation of the pandemic, universities delayed the opening of school. College students must reduce their going out, resulting in their inability to study and participation in social activities, which may affect their learning progress and aggravate their anxiety and depression. Therefore, the mental health problems of college students should not be ignored. This could be the reason why there is no difference between school type and anxiety.

\subsection{Relationship Between Learning Anxiety and Self-Efficacy}

There was a weak negative correlation between learning anxiety and self-efficacy ( $\mathrm{r}=-0.074$, $\mathrm{P}<0.01$ ) (Table 7).

Table 7. Correlation between learning anxiety and self-efficacy

\begin{tabular}{llll}
\hline \multirow{2}{*}{ Self-efficacy } & & Self-efficacy & learning anxiety \\
\cline { 2 - 4 } & Pearson Correlation & 1 & $-.074^{* *}$ \\
\cline { 2 - 4 } & Sig. (2-tailed) & & .012 \\
\cline { 2 - 4 } & $\mathrm{N}$ & 492 & 492 \\
\hline
\end{tabular}

**. Correlation is significant at the 0.01 level (2-tailed).

In order to gets a thorough picture concerning the relationship of learning anxiety and self-efficacy, this study further explored the correlation between the different factors of learning anxiety and self-efficacy below.

Table 8. Correlation between the factors of anxiety and self-efficacy

\begin{tabular}{|c|c|c|c|}
\hline & \multicolumn{3}{|l|}{ Self-efficacy } \\
\hline & Pearson Correlation & Sig. (2-tailed) & $\mathrm{N}$ \\
\hline Self-efficacy & 1 & & 492 \\
\hline teaching mode & $-.386 * *$ & .000 & 492 \\
\hline Class Interaction & .018 & .691 & 492 \\
\hline
\end{tabular}




\begin{tabular}{|c|c|c|}
\hline Class Study and Examination & -.024 & 492 \\
\hline external environment $\quad .001$ & $-.144 * *$ & 492 \\
\hline
\end{tabular}

\subsection{The Influence of English Learning Anxiety on Students'Self-Efficacy}

\subsubsection{The Influence of Learning Anxiety on Self-Efficacy}

As Table 8 illustrates, learning anxiety has an impact on self-efficacy. The fitting degree between the linear equation and the original data is 0.02 (usually $0-1$ ) and there is no sequence correlation. The effect of learning anxiety on learning efficacy is negative (learning efficacy $=20.172-0.059 *$ learning anxiety), that is, the higher the score of learning anxiety, the weaker the sense of learning efficacy. The residual value is small and has linear regression significance.

Table 9. The influence of learning anxiety on self-efficacy

\begin{tabular}{lllllll}
\hline \multicolumn{2}{l}{ Model } & Sum of Squares & df & Mean Square & F & Sig. \\
\hline \multirow{2}{*}{1} & Regression & 158.932 & 1 & 158.932 & 8.174 & $.012^{\text {b }}$ \\
\cline { 2 - 7 } & Residual & 9527.919 & 490 & 19.445 & & \\
\cline { 2 - 6 } & Total & 9686.852 & 491 & & & \\
\hline \multicolumn{2}{l}{ a. Dependent Variable: Self-efficacy } \\
$l$
\end{tabular}

\begin{tabular}{rllllll}
\hline \multirow{2}{*}{ Model } & \multicolumn{2}{l}{ Unstandardized Coefficients } & \multicolumn{2}{l}{ Standardized Coefficients } & & \\
\cline { 2 - 5 } & $\mathrm{B}$ & Std. Error & Beta & $\mathrm{t}$ & Sig. \\
\hline \multirow{2}{*}{1} & (Constant) & 20.172 & .692 & & 29.167 & .000 \\
\cline { 2 - 6 } & $\begin{array}{l}\text { learning } \\
\text { anxiety }\end{array}$ & -.059 & .021 & -.128 & -2.859 & .012 \\
\hline
\end{tabular}

a. Dependent Variable: Self-efficacy

The reason why learning anxiety is inversely proportional to self-efficacy may ascribe that anxiety is actually an emotion. Emotion is a complex psychological phenomenon, which includes emotional experience, emotional behavior, emotional arousal and other complex components (Huang, 2015). The relationship between learning anxiety and learning efficiency can be explained as the relationship between emotional arousal level and work learning efficiency. High level of arousal will reduce the achievement and affect self-efficacy, and when people are not trapped by disgusting stimulation, they are more likely to expect success. There is a question of the best level in all kinds of activities. Generally speaking, people's work efficiency is the highest under the medium intensity motivation. At the same time, the optimal level of motivation varies with the nature of the task: in the easier task, the work efficiency tends to increase with the increase of motivation; in the more difficult task, the optimal level of motivation tends to decrease gradually. This phenomenon is called the "Yerkes -- Dodson Law" (Yerkes \& Dodson, 1908). 


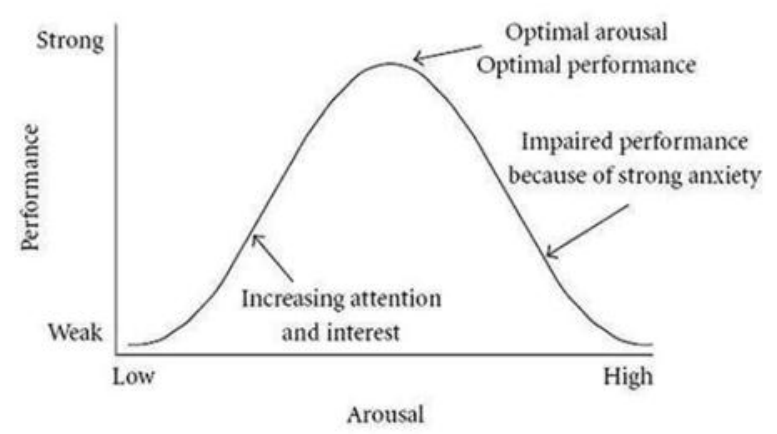

Figure 1. Yerkes -- Dodson Law (Yerkes \& Dodson, 1908)

\subsubsection{The Influence of the Factors of Anxiety on Self-Efficacy}

From Table 10, online teaching mode has an impact on self-efficacy. The fitting degree between the linear equation and the original data is 0.02 (usually 0-1) and there is no sequence correlation. The effect of online teaching mode on self-efficacy is negative (self-efficacy $=23.769-0.687 *$ online teaching mode), that is, the higher the score of online teaching mode anxiety is, the weaker the sense of self-efficacy is. The residual value is small and has linear regression significance.

Table 10. The influence of the factors of anxiety on self-efficacy

\begin{tabular}{lllllll}
\hline & \multicolumn{2}{l}{$\begin{array}{l}\text { Unstandardized } \\
\text { Coefficients }\end{array}$} & \multicolumn{2}{l}{$\begin{array}{l}\text { Standardized } \\
\text { Coefficients }\end{array}$} & & \\
\cline { 2 - 5 } Model & $\mathrm{B}$ & Std. Error & Beta & t & Sig. \\
\hline teaching mode & -.687 & .074 & -.386 & -9.263 & .000 \\
\hline Class Interaction & .035 & .089 & .018 & .398 & .691 \\
\hline $\begin{array}{l}\text { Class Study } \\
\text { Examination }\end{array}$ & -.036 & .068 & -.024 & -.528 & .597 \\
\hline external environment & -.093 & .029 & -.144 & -3.217 & .001 \\
\hline a. Dependent Variable: Self-efficacy & & & & \\
\hline
\end{tabular}

The results indicate that online learning can reduce students' self-efficacy. Because of the global pandemic, students across the country have to study online. This way of learning brings many disadvantages to them. College Students' study time at home is shorter than that at school, and the self-efficacy is low. Compared with the fixed place of school study, strict class time, systematic assessment system, and abundance learning materials, the learning atmosphere at home is not as good as that in school. This makes some students have irregular work and rest, homework procrastination and other phenomena. As a result, the overall efficiency of students studying at home is low. The change of learning environment leads to the increase of external temptation and the decrease of class concentration. There are many videos of students pretending to be online classes, which also reflect a drawback of home-based learning. Home based learning uses the network platform for online teaching, without special supervision and environmental constraints. The convenient online way also 
makes some students difficult to resist the temptation of the outside world and cannot focus on the classroom content. These factors lead to the decline of learning efficiency, and then affect students' self-efficacy.

From Table 10, external environment have an impact on self-efficacy. The fitting degree between the linear equation and the original data is 0.02 (usually $0-1$ ) and there is no sequence correlation. The influence of external environment on self-efficacy is negative (self-efficacy $=20.407-0.093 *$ external environment), that is, the higher the score of external environment anxiety, the weaker the sense of self-efficacy. The residual value is small and has linear regression significance.

The reason for this phenomenon may be that there are many tools used in online learning. Online learning has changed the traditional teaching method. This pure online teaching method is not only a test for students, but also a test for teachers. Even though the school has organized teachers' online teaching training for many times, this pure online learning method is still in the exploratory stage, and most colleges and universities do not have a unified and reliable form. This also leads to different teachers may choose different teaching tools for teaching. Common learning tools are DingDing, Tencent conference, Tencent QQ and so on. As a result, a student may need to use multiple tools to complete the study. In the process of using these teaching tools, it is inevitable that students forget to turn off the microphone, which leads to a lot of noise; the teacher forgets to turn on the microphone also leads to no sound in class; the teachers who are used to writing on the blackboard are not used to it, the network is unstable, the effect of teachers' questioning in class is poor, and the communication between students is reduced. Different family environment has different influence on college students' home study. The influence of family environment on College Students' home-based learning is manifested in two aspects: material conditions and binding force. On the other hand, different families can provide different material conditions; some of them do not have a good network and learning environment. In view of this special group of college students, they have more academic pressure and stronger autonomous learning ability, and the family's binding force on them will be relatively large. In addition, long time with parents, parent-child relationship also has an impact on college students' online learning. These factors lead to their uncertainty about whether they are sure they can complete the task, thus reducing their self-efficacy

\section{Conclusion}

\subsection{Major Findings}

The present study was undertaken to understand the relationship between English learning anxiety and learning-efficacy of contemporary college students under the pandemic situation. The main purpose of this study is to explore the anxiety level of Chinese EFL college students in online English course, how learning anxiety changes with the characteristics of individual learners, the relationship between learning anxiety and self-efficacy, and the extent to which learning anxiety predicts self-efficacy.

The results of the questionnaire survey indicate that most of the students have moderate or 
above learning anxiety level. T test and ANOVA were used to compare the English learning anxiety level of the students in each group from the aspects of gender, grade and institution type. Within the three groups, only students of different grades demonstrated significant differences in learning anxiety level. There are no significant differences in gender and institution type.

In terms of the relationship between self-efficacy and learning anxiety, there is a weak negative correlation between them, and so is the relationship between anxiety factors and self-efficacy. Among the four anxiety factors: teaching mode, class interaction, class study and examination, and external environment, only factors "teaching mode" and "external environment" have correlation with self-efficacy.

Further linear regression analyses of the influence of English learning anxiety on students' self-efficacy were also conducted. The results show self-efficacy will decrease with the increase of learning anxiety scores. In the factors of anxiety and self-efficacy liner regression analysis, self-efficacy will also decreased with the increase of teaching mode, network equipment and environmental anxiety scores.

There are many reasons for the online English learning anxiety, and it has a great influence on the self-efficacy. It is mainly because the research on the psychological factors, gender, future development, emotional arousal level, the present examination system and the status of network equipment are also related.

\subsection{Implications}

Teachers should cultivate students to form metacognitive strategies. Generally speaking, metacognitive strategy means that learners can consciously plan, monitor and evaluate their learning situation, which occupies a dominant position in the learning strategy system (John Hurley Flavell, 1970). Language learning is essentially a process of information processing, and metacognitive ability is the core component of information processing. A large number of studies have confirmed that the success of metacognition will directly affect foreign language learning. The anxiety of students in foreign language classroom may be attribute to the interference of various external factors, such as the pressure of future development, the form of class, network problems, etc., which leads to the failure of metacognitive ability to process the input information. Teachers should try their best to enhance students' awareness of using metacognitive strategies in the process of learning; help students make the direction of learning clear, understand the means and effects of learning, and formulate reasonable learning plans; make students constantly monitor and adjust learning activities, adjust their learning attitude and correct their learning behaviors in time; After the completion of the learning task, teachers should objectively evaluate the learning effect, gradually strengthen the ability of autonomous learning, and reduce the foreign language classroom anxiety under the network multimedia environment.

Teachers should actively use the network multimedia to create teaching situations. Using this method to create a rich teaching situation is conducive to create a harmonious, relaxed and pleasant atmosphere, motivate students' initiative in classroom participation, and stimulate 
students' interest in learning. In the process of teaching, we can enrich learners' emotional experience by means of network-based discussion, role-playing and multimedia courseware made by learners themselves, and strive to create a democratic and equal, relaxed and harmonious classroom atmosphere with students as the main body; It can also implement inquiry learning and network-based cooperative learning. By using Tencent Conference, QQ online chat and other auxiliary tools, learners can fully communicate and cooperate with others in virtual learning environment, arouse learners' desire for knowledge and enthusiasm for participating in classroom activities, and break the closed state of self-learning.

\subsection{Limitation of the Study}

In this study, the sample size distribution is uneven. For example, the number of female is significantly more than that of male, the number of students in private schools is more than that of public and vocational schools, and the number of students above grade three is less.

\section{References}

Bandura, A. (1982). Self-efficacy mechanism in human agency. American Psychologist, 37(2), 122-147.

Chang, C., \& Lin, H. C. K. (2018). Classroom interaction and learning anxiety in the irs-integrated flipped language classrooms. The Asia-Pacific Education Researcher. https://doi.org/10.1007/s40299-018-0426-X

Chen, X. F., \& Luo, X. R. (2012). Anxiety about English learning and online autonomous learning. Journal of Chongqing University of Technology (Social Science), (07), 118-121.

Dai, F. H. (2019). A study on the strategies of College English learners' foreign language learning anxiety based on self-efficacy theory. Journal of Hubei Open University, (16).

Debreli, E., \& Demirkan, S. (2015). Sources and levels of foreign language speaking anxiety of English as a foreign language university students with regard to language proficiency and gender. Language Proficiency, 4(1), 49-62. https://doi.org/10.5296/ijele.v4i1.8715

Fang, F., \& Yao, B. X. (2005). Research on life pressure and mental health of female college students. Journal of China Women's University, 17(006), 34-39. https://doi.org/10.3969/j.issn.1007-3698.2005.06.006

Haley, M., Romero Marin, M., \& Gelgand, J. C. (2015). Language anxiety and counseling self-efficacy. Journal of Multicultural Counseling \& Development, 43(3), 162-172. https://doi.org/10.1002/jmcd.12012

Horwitz, E. K., Horwitz, M. B., \& Cope, J. (1986). Foreign language classroom anxiety. Modern Language Journal, 70(2), 112-127. https://doi.org/10.2307/327317

Karatas, H., Alci, B., Bademcioglu, M., \& Ergin, A. (2016). An investigation into university students - foreign language speaking anxiety. Procedia Social \& Behavioral Sciences, 232(2016), 382-388. https://doi.org/10.1016/j.sbspro.2016.10.053

Liu, M. (2006). Anxiety in Chinese EFL students at different proficiency levels. System, 34(3), 


\section{Macrothink}

301-316. https://doi.org/10.1016/j.system.2006.04.004

Lu, B. Y., \& Ren, Y. Q. (2012). Walk in the clouds: cloud computing in education of China. Journal of Distance Education, 30(001), 62-67. https://doi.org/10.3969/j.issn.1672-0008.2012.01.007

Spielberger, C. D. (1972). Anxiety as an emotional state 1. Anxiety, 1(6-7), 23-49. https://doi.org/10.1016/B978-0-12-657401-2.50008-3

Wang, F. (2019). College Students' foreign language learning anxiety and intervention strategies under the network multimodal environment. Overseas English, 409(21), 120-121.

Wang, L., He, J. L., Xie, L. Y., Fang, Y. Y., \& Gan, X. X. (2012). Psychological pressure of female college students and its influence on Employment. Management Observer, 000(020), 141-142. https://doi.org/10.3969/j.issn.1674-2877.2012.20.095

Wang, Y. (2016). Research on English learning anxiety of non-English majors under flipped class model. Journal of Guangxi Normal University (Philosophy and Social Sciences Edition).

Xue, M., \& Cui, Y. Y. (2011). An empirical study on classroom learning anxiety of secondary vocational English learners in content-based instruction. Overseas English, 000(005), 85-86.

Yin, Z. Y. (2011). On the sources and implications of foreign language classroom anxiety in network and multi-media environment. Journal of Yichun University, (06), 178-180. https://doi.org/ 10.3969/j.issn.1671-380X.2011.06.063

Zhao, Z. Y. (2017). Research on College Students' English learning anxiety under the network environment. Doctoral Dissertation.

\section{Copyrights}

Copyright for this article is retained by the author(s), with first publication rights granted to the journal.

This is an open-access article distributed under the terms and conditions of the Creative Commons Attribution license (http://creativecommons.org/licenses/by/4.0/) 